\title{
A PROPÓSITO DE LA LITERATURA SOCIAL Y CON ÁNIMO DE POLÉMICA: CUADERNOS PARA EL DIÁLOGO. 1963-1975
}

Ruth Cubillo Paniagua

\begin{abstract}
RESUMEN
Mediante el estudio de los artículos sobre literatura publicados en una revista cultural española, Cuadernos para el diálogo, entre 1963 y 1975, se analizan diversos momentos de la novela española contemporánea, en especial, la novela social y toda la polémica desatada en torno a ella durante la década de 1960.
\end{abstract}

\begin{abstract}
The author studies articles about literature published in the Spanish cultural magazine - Cuadernos para el diálogo — between 1963 and 1975, in order to analyze various tendencies within the contemporary Spanish novel, in particular the "social novel" and the polemics which surrounded this approach in the 1960's.
\end{abstract}

\section{Aspectos generales}

Las revistas culturales constituyen un espacio de diálogo en el que se perfilan, desarrollan y difunden diversas nociones de cultura, identidad cultural, arte, literatura y nación, entre otras. Estas revistas son instituciones culturales que poseen una importante significación histórica; muestra de ello es el interés cada vez mayor que investigadores de diversas disciplinas ponen en su estudio.

En las revistas culturales se privilegian unos textos y se excluyen otros, se protegen y conservan los discursos para hacerlos circular en determinados espacios y según ciertas reglas. Estas publicaciones contribuyen a configurar el discurso cultural, que en buena medida es un discurso simbólico de las sociedades en que se producen y circulan, y de los diferentes grupos sociales que conforman esas sociedades.

En el caso particular de este artículo, se llevará a cabo un análisis de la revista española Cuadernos para el diálogo, concretamente de los artículos publicados entre 1963 y 1975 acerca de la literatura en general y de la novela en particular.

Cuadernos para el diálogo publicó su primer número en octubre de 1963 y desde su inicio tuvo entre sus temas de interés la literatura. Esta revista cultural se estructura en diversas secciones y aborda temáticas variadas, tales como: educación, política, religión, filosofía 
y literatura, entre otras. Publica números ordinarios mensualmente, así como números extraordinarios y suplementos, estos dos últimos con menor regularidad y dedicados a un tema en particular. En sus diversas secciones, esta revista presenta una serie de géneros discursivos, como la crítica, la crónica, las notas, la entrevista, la encuesta, los manifiestos y declaraciones, y la polémica, que en algunas épocas cobra especial relevancia.

En las páginas que siguen se analizarán los artículos que originaron y alimentaron luego una polémica: la generada en Cuadernos para el diálogo en torno a la denominada "literatura social", polémica que se desarrolla especialmente entre 1969 y 1971, gracias sobre todo a la publicación de dos números extraordinarios y un suplemento ${ }^{1}$. También se hará alusión a otros artículos que no se enmarcan estrictamente dentro de esta polémica, pero que se refieren igualmente a la "literatura social".

En términos generales, se puede afirmar que los artículos publicados entre 1963 y 1967, cuya temática central era la literatura, abordan temas como el compromiso del escritor, la función social de la literatura, las relaciones entre la literatura y la sociedad, la evolución de la novela española y el subdesarrollo literario, entre otros. En estos ensayos, aunque a grandes rasgos, se continúan "defendiendo" los postulados básicos del realismo social, se comienzan a plantear ciertos cuestionamientos a las posturas más radicales que concebían la literatura como un mero vehículo o instrumento de transformación de la realidad; es decir, se cuestiona la capacidad de la literatura para "cambiar" el mundo, así como la obligación del escritor de comprometerse, incluso políticamente, en esa transformación.

Todos estos cuestionamientos alcanzan su punto álgido en Cuadernos para el diálogo entre 1969 y 1971, debido especialmente a la publicación de dos números extraordinarios y un suplemento dedicados a examinar la evolución de la literatura española de la posguerra (de 1939 a 1969), la literatura española a 30 años del siglo XXI y las relaciones entre la literatura y la política, concretamente el realismo social español, tal y como señalamos líneas atrás.

El objetivo de este artículo no es reproducir las diversas caracterizaciones, clasificaciones y periodizaciones que la comunidad hermenéutica ha elaborado para referirse a la novela social española (o novela española de posguerra, o novela realista o novela española contemporánea). Son muchos los textos críticos que abordan esta temática y lo hacen desde distintas perspectivas ${ }^{2}$.

Nuestro objetivo es dar cuenta, mediante el análisis de los ensayos retomados para este ensayo, del proceso de matización, cuestionamiento y crisis última que experimentó la denominada novela social española y que se vio plasmado en Cuadernos para el diálogo durante los años que hemos establecido como fechas límite para esta investigación, es decir, 1963-1975.

Como señala la gran mayoría de críticos, los últimos años de la década del 50 y los primeros años de la década del 60 constituyen un momento crucial para la "nueva novela" española, pues muchos de los escritores que hasta esa fecha habían formado parte del grupo llamado "neorrealista" (Sánchez Ferlosio, Ignacio Aldecoa, Jesús Fernández Santos, Carmen Martín Gaite) o bien de los denominados "realistas sociales" (Juan García Hortelano, José Manuel Caballero Bonald, Juan Goytisolo, Daniel Sueiro, Jesús López Pacheco, Alfonso Grosso y otros $)^{3}$ comienzan a cuestionarse la validez de algunas de las premisas fundamentales del realismo social que hasta ese momento ellos habían defendido con tanta vehemencia. 
En palabras de José Corrales Egea:

Entre 1958 y 1960 la (...) “nueva novela” española llega a una especie de encrucijada, bifurcándose en dos direcciones. El impulso inicial recibido al filo de medio siglo, y hasta ahora en dirección única, se secciona.(...) El grupo que personaliza, que representa a la nueva novela y que da el tono se nos había presentado bastante homogéneo, a pesar de los diferentes temperamentos de los escritores que pasaron a formar parte de él. Todos participan de idéntico anhelo.(...) Todos se distinguen y asemejan en el deseo de desvelar, de descubrir la realidad cotidiana y común española, para lo cual adoptan el procedimiento de la elaboración narrativa que ya conocemos y que con El Jarama había desembocado en un riguroso realismo "objetivista", entroncando con el beavihorismo psicológico. En el umbral de la década de los años 60, esa novela toma dos direcciones. De un lado, seguirán apareciendo algunas obras que, fieles a aquel procedimiento ya madurado y puesto a punto, lo intensificarán todavía más (...) Por otro lado, empiezan a aparecer otras obras menos radicales, adaptadas a un objetivismo y a un realismo que llamaremos atemperado, atenuado; e incluso se intentará una novela nueva de otro género, no forzosamente realista, o de un realismo diferente, concebido desde otra perspectiva" (1971: 83).

Tiempo de silencio, de Luis Martín Santos, publicada en 1962, es considerada como la obra que desencadena esta ruptura entre dos modos de novelar y que posibilita la evolución de la novela española hacia otros ámbitos. Sus formas de narrar, su estilo y su concepción misma de la novela como género, no se parecen en nada a las que venían empleando los novelistas sociales ${ }^{4}$.

Por su parte, Últimas tardes con Teresa, publicada en 1966, es considerada por muchos críticos como una "consecuencia del alerta renovador difundido por Tiempo de Silencio" (Sanz 1980:137), especialmente en lo que respecta a su tratamiento formal.

Este clima de "sofoco" (como apunta Corrales Egea), esta inquietud por ir más allá de lo meramente testimonial y de poner más atención a lo formal, esta ruptura o "bifurcación”, está muy presente en los ensayos sobre literatura que se publican en Cuadernos para el diálogo. Ya desde 1963 — año en que se publica el primer número de esta revista- quienes escribían aquí sobre literatura (que por lo demás eran precisamente los involucrados en el mundo literario, es decir, autores, críticos literarios y editores) planteaban ciertos matices en conceptos clave del realismo social, como por ejemplo el compromiso social del escritor y la función social de la literatura.

Muchos novelistas, como veremos más adelante, reconocerán sin tapujos que el realismo social se les estaba -por decirlo de alguna manera- quedando corto, y no tenían reparos para aceptar que, aunque en su momento lo consideraron la mejor opción, ahora pensaban que era necesario abrirse hacia nuevos horizontes y brindarle nuevas oportunidades de desarrollo a la novela, transitando por nuevos caminos.

\section{2. ¿Por qué la novela?}

Es pertinente señalar que la mayor parte de los ensayos que aquí retomamos se refieren a la novela, en especial a la novela social. Aunque algunos se dedican a la poesía o al teatro, la novela y la polémica generada en torno a la validez de los principales postulados del realismo social presentes en las novelas sociales, ocupan la mayor cantidad de páginas. 
Francisco Álamo opina que las novelas escritas por los autores llamados neorrealistas y por los llamados realistas sociales, procuraban lograr que el pueblo despertara y se diera cuenta de todo aquello que le había sido ocultado u oscurecido en las páginas de la literatura española, es decir, procuraban generar en el pueblo un proceso de toma de conciencia. Para Álamo esta era una postura de responsabilidad por parte de los novelistas, una actitud de "precocidad" ante el enorme desierto cultural en que se hallaba inmersa España en aquellos años de posguerra. En opinión de este autor, la novela constituye el espacio en el que va a "jugarse esta partida", ella es la protagonista máxima y acaparadora de todas las tensiones que circulaban y la carta a la cual apostaron los autores realistas.

Por estas razones, en palabras de Juan Carlos Rodríguez (1985: 7), la novela social se convirtió en:

\begin{abstract}
(...) el personaje en torno al cual va a girar no sólo la problemática literaria, sino incluso económica, pues el funcionamiento del Aparato Editorial en España, desde el 39 hasta hace muy poco, ha pasado directamente por la historia de la novela, por las evoluciones, fluctuaciones, alzas y bajas de los diversos momentos novelísticos (...) la novela como símbolo mítico en un terreno en el que parecen enfrentarse dos contendientes claves dentro de la perspectiva europea y española: la novela es una especie de ring donde lucha el mito franquista contra el mito antifranquista.
\end{abstract}

El realismo crítico constituyó el medio considerado por los intelectuales como el más eficiente para enfrentarse al caos y a la parálisis generados por la cultura oficial, y poco a poco "fue fundamentando una concepción en la descripción de la realidad que, superando las éticas de las bienaventuranzas iniciales del neorrealismo, se orientara hacia una denuncia de las injusticias en los más débiles y explotados que estaba produciendo la descarnada acumulación de capital que nuestra "occidentalización" y "modernización" necesitaba. Este grupo realista (...) consideró sus escrituras como un acto antifranquista" (Álamo 1996: 116-7).

Así, muchos de los novelistas sociales militaban en el Partido Comunista, entre ellos Alfonso Grosso, Armando López Salinas, Luis Goytisolo, Juan Marsé y Antonio Ferres, y muchos otros no militaban en el PC pero fueron "compañeros de viaje", de alguna manera estuvieron cerca del Partido y, por lo tanto, fueron considerados demócratas-antifascistas. En Cuadernos para el diálogo escribió una buena parte de estos militantes y "compañeros de viaje", aunque también colaboraron personas menos "involucradas" o "comprometidas" con la causa. A analizar sus artículos sobre literatura publicados en esta revista nos dedicaremos en las páginas que siguen.

\title{
3. Realismo social sí, pero...
}

Como ya mencionamos, Cuadernos para el diálogo publicó su primer número en octubre de 1963. En ese número aparece un solo artículo relacionado con la literatura. Se titula "Compromiso del escritor con el hombre de su tiempo" y lo firma el novelista Luis CastilloPuche. Para empezar, Castillo-Puche señala que la palabra "compromiso", aplicada al escritor, está de moda, y él se propone analizar de qué clase de compromiso se trata, así como plantearse "si no existirá otro compromiso diferente y más profundo que ese compromiso cacareado y actual del que tanto se habla" (1963: 12). 
Considera este autor que la sociedad actual trata de comprometer al escritor con la moral imperante, la cual a menudo es una moral llena de vicios y errores, una falsa moral, de modo que el escritor se ve coaccionado por esa sociedad y esto atenta contra su condición de "creador", "que hace siempre de su libertad el más preciado botín de cualquier régimen político" (1963: 12).

Por esta razón, Castillo-Puche opina que el único compromiso admisible para el escritor es "su compromiso con el hombre, con el individuo, que sufre o disfruta las condiciones que la sociedad, la política o las leyes le imponen”. Así, continúa el autor, el escritor no puede "venderse" ni "entregarse", su deber es mantenerse alerta, abrir muy bien los ojos para asimilar lo que acontece a su alrededor, denunciar la injusticia y procurar evitar la uniformidad y la masificación. Para lograr esto escribirá una literatura de "protesta”, pero Castillo-Puche se apresura a aclarar lo que él entiende por "protesta" y al hacerlo toma distancia de ciertos postulados del realismo social, pues afirma lo siguiente:

Nadie crea, sin embargo, que la novela-protesta consiste en formular protesta alguna, ni mucho menos en hacer de la novela manifiesto político o social. Describir, descubrir, testimoniar... En el simple testimonio puede encerrarse la mayor protesta, la mayor rebeldía (1963: 13).

Por su parte, Fernando Morán (1964:16), en el artículo titulado "Novela y realidad social", también plantea ciertos cuestionamientos a las posturas más radicales del "realismo socialista". En primer término, señala que el realismo como estilo literario es anterior a la "fijación" del marxismo y que en la literatura española nunca ha dejado de estar presente. Además, considera que en toda obra literaria se da una "transformación ininterrumpida de las realidades desconocidas en conocidas; cuando lo son dejan de ser patrimonio del novelista para pasar al del periodista o del cronista" y, siguiendo a Nathalie Serraute, opina que el novelista debe gozar de la máxima libertad para elegir las formas y los procedimientos con los cuales aprehenderá esta realidad informe y en perpetua transformación. Para el caso concreto de España, esboza una especie de alerta a los escritores:

Cultura muy mimética en sus creaciones elevadas la española, sus escritores podrían caer en un cierto desconcierto si creyesen que la salida de sus dilemas se encuentra en la imitación de una u otra doctrina (19).

Como evidencia de que, en su opinión, el realismo social ya se está agotando o se ha agotado, señala Morán que la nueva novela española debe dar cuenta, tanto en el nivel de sus contenidos como en el de sus técnicas, de los grandes cambios experimentados por la sociedad española de aquellos años, en especial su paso del "infradesarrollo" al "semidesarrollo" económico. Por eso considera que "la próxima gran novela será aquella que acierte con la técnica apropiada para transmitir la compleja interacción de los distintos niveles sociales e ideológicos de la vida nacional en una unidad coherente y artística" (1964:19).

En esta misma línea de un cierto retorno a la preocupación "estética", el dramaturgo Alfonso Sastre, en su artículo "Aproximación a la estética”, hace referencia a la tensión existente entre los partidarios del arte por el arte y los defensores del utilitarismo radical del arte, y señala: 


\begin{abstract}
En el título del breve texto que presento puede verse - y está bien que se vea- una invitación dirigida a algunos bienintencionados fugitivos del tema estético; tema del que se huye a veces como del diablo, por adivinar en él la trampa del conformismo. Tales escritores o artistas piensan, quizá, el tema estético desde la (hoy anacrónica) tensión polémica (nosotros agregaríamos que, a juzgar por el contenido de los ensayos publicados al respecto en Cuadernos para el diálogo, tal polémica no se podría calificar precisamente de "anacrónica") que enfrentaba el principio del arte por el arte -la autonomía de lo estético ("esteticismo")- con el opuesto principio de un utilitarismo radical; y en una circunstancia como la española, toman partido por este último, desde la consideración moral de que todo sacrificio es poco para la causa de la transformación radical de nuestro país. Enorme error por el que se prescinde, justamente, del instrumento propio de los escritores literarios y artistas para su operación social: el instrumento estético (1964: 12).
\end{abstract}

A partir de los anteriores planteamientos, propone Sastre una solución al dilema del escritor que pase por la vía dialéctica y que se fundamente en la "imaginación". Postula entonces las siguientes tesis: "el arte (literario) "es-y-no-es" un juego; el arte "es-y-no-es" política; el arte "es-y-no-es" conocimiento" (Sastre 1964: 12), tesis que a su entender son posibles porque "el arte es un juego (imaginación) peligroso (sobre lo real); el arte es una política "imaginaria"; el arte es una investigación "imaginaria"” (ídem).

Sastre concluye, sin apartarse por completo de los postulados realistas, que el arte es un "útil inútil actual", puesto que debe ser capaz de generar en el público un proceso de toma de conciencia, a partir de lo cual pasaría a ser un "inútil actual futuramente útil". Ante esta situación, Sastre considera que el escritor debe completar su "compromiso estético" con el trabajo científico y la actividad propiamente política, porque, para él, "hacer literatura no es bastante" (14).

En su ensayo titulado "Subdesarrollo literario", Antonio Martínez Menchén apunta que, en su opinión, la novela española actual es una novela subdesarrollada, en tanto que:

(...) la novela como género literario ha alcanzado en su evolución un nivel en cuanto a preocupaciones técnicas, temáticas y planteamiento general, y este nivel de desarrollo, común (...) a una buena parte de la literatura europea y americana, no ha sido alcanzado por la novela española (1964: 18).

Explica el autor las causas que en su opinión han ocasionado tal "subdesarrollo" y señala que la novela española continúa, en lo referente al planteamiento y a la técnica, estrechamente relacionada con las posturas de la novelística del siglo XIX, de modo que los jóvenes novelistas, "que desde el punto de vista de preocupación ideológica y de enfrentamiento con la realidad pueden considerarse con razón y orgullo como plenamente actuales y válidos, han realizado su importante obra dentro de unos moldes completamente desfasados por la novelística universal (...) Una cosa es la tradición realista y otra el novelas como en el siglo XIX” (Martínez 1964: 18).

Así, Martínez también cuestiona la validez de los planteamientos "estéticos" del llamado realismo social imperante en las dos décadas posteriores a la guerra civil, pues en su opinión han sumido a la novela española en un grave desfase con respecto a la novela universal, en ese mencionado "subdesarrrollo" novelístico. Finalmente, Martínez (19) se plantea la siguiente interrogante: “¿qué puede hacer -el escritor español- para conjugar esta antinomia de escritor español y escritor de nuestro tiempo?”, y responde lo siguiente: 
Es difícil la solución. Acaso lo mejor sea intentar establecer de nuevo el vínculo allí donde se rompió. Comenzar de nuevo, ligándonos al momento español y universal en que estábamos cuando se produjo el vacío, y partiendo de ahí, avanzar como sea, si es posible quemando etapas. Así, lo mismo que ocurre en la economía, la nuestra será una literatura subdesarrollada, pero al menos en vías de desarrollo.

Antonio Ferres (1965:17) en su ensayo "Literatura y sociedad", objeta lo que afirma Martínez en cuanto al "subdesarrollo novelístico" y señala que, si bien es cierto las técnicas y los planteamientos de la nueva novela que se escribe en el resto del mundo le están ayudando a evolucionar a la novela española, "es ingenuo pensar que el desarrollo o el subdesarrollo literario y artístico ha sido alguna vez paralelo con el desarrollo industrial." Considera Ferres que:

(...) el llamado realismo (la postura realista) en novela es una resultante estética de una posición crítica ante la vida y el contexto social —desde La Celestina, la Picaresca o el Quijote, pero es también un ansia por conocer los aspectos múltiples de la realidad; aspectos múltiples y contextos que hay que ampliar hoy (Ferres 1965: 17).

Por estas razones, en su opinión, “creer que el arte y la literatura son fenómenos espirituales sin relación directa con la sociedad, en el seno de la cual se desarrollan, es caer en una vieja trampa" (Ferres 1965:17). De manera que, continúa Ferres, la nueva novela española está naciendo del conflicto entre la realidad cambiante y la forma de expresarla. Así, este autor se muestra mucho más apegado que Martínez a los postulados del llamado realismo social, aunque él también plantea ciertos matices que considera indispensables para adaptarse a las exigencias de los nuevos y cambiantes tiempos.

Y mucho más radical en cuanto a su apego al realismo social se muestra Antonio López Salinas, quien en su artículo "Notas para un diálogo sobre el realismo en la literatura", señala:

El realismo (...) no es una cuestión de técnica o forma, sino del contenido de la obra, de su sentido y relación con la sociedad, con el ser humano. Por ello el realismo no depende, por más que participe de ello, y sea necesario que marche en vanguardia, de la evolución formal de la literatura, sino de la evolución general de la sociedad (1965:16).

Para López Salinas, la misión del escritor no es sólo explicar el mundo, sino transformarlo (p. 16).

Por su parte, Antonio Ferres publica en 1965 un ensayo titulado "Evolución de la novela española", en el cual realiza un recuento de lo que a su entender ha sido el camino recorrido por la novela española después de la guerra civil. Después de hablar de los "naturalistas", de los "neorrealistas" y de los "realistas sociales", se refiere a la obra de Luis Martín Santos, Tiempo de silencio, como una novela de ruptura que se plantea una visión macrocósmica de la sociedad y del hombre, y que da cuenta de toda una compleja serie de cambios de actitud, sociales e ideológicos (incluidas muchas frustraciones). Esta corriente del "macrorealismo", opina Ferres que ha sido continuada por otros "nuevos novelistas" como Martínez Menchén, Félix Grande, Alfonso Grosso, Rafael Conte y otros.

Pero más allá de estas rupturas, señala Ferres que lo que verdaderamente desalienta al realizar un recorrido por la novela española es "la discontinuidad novelística o histórica, los 
"apagones" novelísticos e históricos, capaces de durar medio siglo, la nada" (Ferres 1965:28). Al parecer, ya en 1965 Ferres se planteaba el agotamiento del modelo realista social y por eso afirmaba que en aquellos años los novelistas se encontraban:

\begin{abstract}
(...) con un pie en el aire, recapacitando. La fiera de la nada (...) parece en ocasiones que va a vencer, que ha aniquilado, cansado, consumido, derrotado por hambre, puesto de rodillas, adocenado, secuestrado, violado, disuelto los novelistas. Pero la fiera de la nada es sólo un vacío en la sangre del mundo; un vacío que hasta obliga al mundo a caminar a saltos, a tirones, a cruentos latidos. Y el novelista parece darse cuenta de todo esto. Es curioso.
\end{abstract}

Por su parte, Dolores Medio (1966:29), en su ensayo "Comentarios en torno a la novela social”, realiza también ciertas matizaciones a los conceptos básicos del realismo social. Ya desde el primer párrafo de su artículo señala la importancia que por aquellos años tenía esta temática, y apunta: "He elegido como tema para el diálogo algo que me parece de gran interés, por tratarse de una cuestión de actualidad, bastante discutida: lo social en la Literatura."

El primer matiz que introduce se relaciona con el tema del compromiso del escritor, pues ella opina que el escritor "auténtico" ha estado siempre comprometido con su tiempo y que su obra posee, de una manera más o menos perceptible, un contenido social. Pero en su opinión:

(...) el novelista no debe hacer de una manera deliberada novela política o novela católica, o novela social, porque corre el riesgo antiestético de convertir su obra en un sermón o en un panfleto vulgar. Debe hacer, simplemente, literatura (29).

Medio establece una clara definición de lo que en su opinión cabe dentro de lo denominado "social", la cual sin duda amplía bastante los límites establecidos por los realistas sociales más radicales. En este sentido, señala:

(...) lo social no debe referirse sólo a los problemas de las clases trabajadoras, aunque en ellas tenga su origen, ni mucho menos reducirse a bucear en los bajos fondos y llevar a la novela a las criaturas que se debaten en medio de todas las miserias. Lo social debe abarcar un concepto más amplio, para recoger todas las manifestaciones del hombre en su vida de relación. Según esto, una novela realista o una obra de teatro, o una película, cuyos personajes se mueven dentro del estrecho marco de la clase media, o de la burguesía, y aun de la aristocracia, puede ser -suele ser- una obra social si no se trata de un merengue rosa (1966: 31).

Después de plantear estas ampliaciones y otras matizaciones más respecto de las nociones fundamentales del realismo social, Dolores Medio concluye que "si la novela es un espejo pasado a lo largo del camino y va recogiendo en sus diferentes géneros el vivir del hombre, forzosamente, y en cada género que cultive, reflejará su dependencia de lo social" (Medio 1966: 32).

En 1969, Fernando Morán, en su artículo "La novela: entre el subdesarrollo y la sociedad de masas", se pregunta nuevamente "las razones de la dificultad para que la novela española actual, sin dejar de cumplir uno de sus objetivos — ser fiel a la realidad — se despojase de sus evidentes limitaciones" (61). Para Morán, ya desde 1959 era evidente que la realidad por 
novelar no era solamente la inmediata, la cotidiana y, en su criterio, "cuando el escritor es inteligente, mucho más cuando toma en serio su función social, piensa que debe exigirse coherencia entre la realidad y su procedimiento literario" (63).

Por estas razones, Morán opina que los nuevos novelistas deben lanzarse a la búsqueda de nuevas posibilidades narrativas, innovando en la técnica y en el estilo, con el fin de dar cuenta de la compleja y heterogénea realidad, así como de sus distintos niveles, y del paso de una situación social, política y económica de infradesarrollo a una de semidesarrollo. Resume lo anterior con las siguientes palabras:

Toda la cuestión reside en acertar con procedimientos que con la justeza necesaria puedan transmitir una síntesis de los distintos niveles de la realidad. Si "La Colmena" fue la gran novela del infradesarrollo, la gran novela actual será aquella que acierte con la técnica y lenguaje apropiados para captar la compleja interreacción de los distintos niveles sociales e ideológicos de la vida nacional en una unidad coherente y artística (1969: 70).

Morán, así como los demás ensayistas que hasta ahora hemos citado, desde diversas perspectivas y con distintos matices, parecen dar cuenta del agotamiento experimentado por la llamada novela social. Coinciden al afirmar que la cambiante realidad demanda ahora nuevos procedimientos narrativos. Muchos de los cuestionamientos que se plantean estos autores son precisamente los que alcanzan su punto álgido en los ensayos que analizaremos a continuación.

\section{Se acentúa la polémica}

Se puede decir que el número extraordinario 14, titulado "30 años de literatura narrativa y poesía española. 1939-1969”, representa el inicio de un proceso que acentuará marcadamente la polémica entre quienes defendían más radicalmente los postulados del realismo social y quienes planteaban la necesidad de incursionar en nuevas formas narrativas.

Desde las páginas de presentación de este número extraordinario (encabezadas con la interrogante “¿Qué es la literatura?”) se hace alusión al inevitable cuestionamiento de los presupuestos literarios imperantes en aquel momento, espíritu que alienta la mayoría de los ensayos que en él se publican. En este sentido, los editores señalan:

En un mundo en el que todo lo fundamental está por resolver era inevitable cuestionar el papel y la función de la literatura, sus contradicciones y también sus servidumbres. La impugnación por tanto de la literatura era inevitable (1969: 5).

Salvador Clotas (1969) es quien firma el primero de los ensayos, el cual se titula "Meditación precipitada y no premeditada sobre la novela en lengua castellana." ${ }^{\circ}$ Aunque la primera frase de su ensayo resulta poco optimista, pues afirma que "la novela es un género en decadencia", rápidamente se apresura a puntualizar que esta decadencia es extensible a muchas otras manifestaciones culturales y que más bien no se atrevería a afirmar

(...) que la novela se acaba. Quizá la literatura se acabe. Pero me parece que lo más correcto es pensar que de momento no se acaba la novela, ni la poesía, ni nada. Caduca una concepción anticuada de la cultura, unos estilos y formas románticos y de espaldas a las nuevas posibilidades 
que la era tecnológica ofrece. No sabemos a qué llamará novela la nueva cultura o si desterrará la palabra como arcaísmo inútil. (...) Desde hace años se habla de antinovela; es una palabra cómoda y expresiva (8).

Una vez aclarado esto, Clotas hace un recorrido por la novela española producida a partir de 1939 y distingue tres períodos para él cronológicamente desiguales y no precisables:

El primero se inicia en 1939 y se prolonga, más o menos, hasta los primeros años de la década del cincuenta. Es una novela que hace sus tanteos en terrenos harto conocidos: lo psicológico, lo social, la prosa poética (...) La figura que domina este período es la de Camilo José Cela (...) En 1953 se afianza una novela de características bien distintas, que apuntaban ya desde la primera obra de Ana María Matute: Los Abel. Dos novelas se sitúan en el pórtico de este período: El Jarama de Sánchez Ferlosio, y Juegos de manos, de Goytisolo (...) A continuación se desarrolla, alrededor sobre todo de la editorial Seix-Barral, un movimiento narrativo que se llamará a sí mismo "realismo objetivo". A partir de 1962 aproximadamente, esta novela entra en crisis, y los años siguientes hasta el presente constituyen uno de los períodos más grises y desolados que ha conocido la novela española (8).

Las últimas líneas de esta extensa cita expresan de una manera bastante clara la crisis y el agotamiento que en opinión de muchos escritores y críticos experimentaba desde hacía años la novela social española, especialmente en cuanto a técnicas, estilos, utilización del lenguaje y formas narrativas. Aunque ya en 1969 se habían publicado algunas novelas "experimentales", autores como Clotas seguían considerando que esto no era suficiente para sacar de su profunda crisis a la novela española, pues muchas de estas obras realizaban tal suerte de experimentos lingüísticos -y formales en general- que llegaban a generar un profundo nivel de incomunicación entre autores y lectores, o entre textos y lectores, lo cual en su criterio también resultaba perjudicial.

En este sentido, la conclusión a la que llega Clotas es contundente y para finalizar su extenso ensayo señala las dos causas — que para él son las más importantes— del fracaso de la joven novela española:

La primera, un prejuicio sociológico y casi estadístico en su apreciación de la realidad, que, renunciando a intuiciones más rentables para la literatura, le ha hecho caer en ese falso realismo (...) tanto como decir que la literatura no necesitaba de la imaginación (...) Creo que únicamente desarrollando un género imaginativo podrá alcanzar la novela una noción de realidad más compleja, que vuelva a ser factible y útil a la realidad limitada y cotidiana que la literatura no debe en modo alguno imitar, sino sustituir (...) Por otro lado, hay que resaltar una evidente confusión en lo que a las posibilidades de lo literario se refiere. Como escribió Pavese: "Non si e mai visto che una poesia abbia cambiato le cose." De lo cual no es forzoso deducir, como hace la crítica derechista, que sólo es posible una literatura no comprometida, sino que los límites de lo literario son demasiado notorios para pretender que una obra literaria pueda ejercer una función no literaria." (17)

En este mismo orden de ideas, Carlos Barral, "escritor de poemas y editor de novelas" —como él mismo se describe_- en su artículo "Reflexiones acerca de las aventuras del estilo en la penúltima literatura española", coincide con Clotas al afirmar que en las poesías y las novelas producidas por los llamados escritores de la "generación del medio siglo": 
(...) la característica más sobresaliente de la historia de los estilos (...) me parece ser la extrema pobreza, la casi indigencia (...) Todos sabemos que, desde todos los puntos de vista, la historia de la novela española de posguerra debe escribirse alrededor de unas cuantas excepciones que puntean una terrible norma general: el equilibrio de mediocridades (...) En fin, hablar de la evolución estilística de la poesía y la novela españolas de posguerra es como ponerse a meditar sobre la decadencia de las grandes familias. (1969: 39)

Cuando Barral se refiere a la poética de la novela social, explica muy claramente que su principal característica era la despreocupación —e incluso el desprecio— por lo estético, al lado de su recia voluntad de denuncia de las injusticias de que eran víctimas las clases populares. Al respecto, señala:

La poética de la novela social partió de presupuestos estrictamente ideológicos, de ideas generalmente poco matizadas sobre presuntas funciones de revolución o al menos de transformación social atribuidas a la práctica de la literatura, ideas que implicaban el desprecio, a menudo confeso, de cualquier planteamiento estético (...) El realismo social fue, desde el punto de vista del estilo, un naturalismo depauperado, $\mathrm{y}$, desde ese mismo punto de vista, uno no puede menos que alegrarse de lo de prisa que cambian las modas (1969: 41-2).

Sin embargo, a pesar de la evidente crisis -y casi muerte- del realismo social, Barral sí percibe la aparición en los últimos años (a partir de 1966 o 1967) de una narrativa nueva, la cual a su juicio era en aquel momento "inmadura, pero sugerente" $\mathrm{y}$, sobre todo, novedosa en lo formal. Se refería sin duda a las novelas experimentales que hacia las fechas que él señala ya habían comenzado a desfilar por el panorama novelístico español, pero que tampoco pasaron de ser una moda pasajera. Algunos críticos opinan que estas nuevas ansias experimentales se vieron incentivadas por la aparición de ciertos premios literarios, en especial del Premio Biblioteca Breve, en cuyas bases se sugería a los participantes la novedad estilística. ${ }^{7}$

En 1970 se publica el número extraordinario XXII, titulado "Literatura española: a 30 años del siglo XXI", y aquí desde el editorial se hace referencia a la polémica generada por el número extraordinario XIV (1969). Los editores señalan que "este nuevo número extraordinario tenía su motivación, ya que no sólo su origen, en otro anterior, aparecido en mayo de 1969, que levantó cierta polémica periodística” y apuntan además el propósito del nuevo número:

\footnotetext{
Ahondar en las raíces de la literatura española moderna a partir de dos conmemoraciones actuales (el centenario de Gustavo Adolfo Bécquer y el cincuentenario de Benito Pérez Galdós), para proyectarse en un futuro, aventurable desde un presente incómodo y ciertamente crítico, no sólo por unas dificultades previas (...), sino también por la búsqueda de una identidad que nadie sabe exactamente, o ni siquiera de manera aproximada, donde puede encontrarse. (...) En el pequeño o gran mundo de la literatura española presente, son muchos los factores acumulados que señalan la existencia de esa crisis (1970: 3).
}

Manuel Vázquez Montalbán publica en este número un artículo titulado "Tres notas sobre literatura y dogma". Cuando se refiere a las relaciones entre literatura y realidad y a la "pretendida" (desde la perspectiva del realismo objetivista) capacidad de la literatura para transformar esa realidad, Vázquez Montalbán señala: 
(...) es imposible una explicación última de la Literatura sin el concurso de la Historia económica, social y política. Y es inútil un conocimiento y una valoración real del hecho literario a base de la aplicación de esquemas trasladados no ya del campo de las ciencias sociales, sino de la más coyuntural estrategia político-tribal (1970: 21).

Después de plantear esta premisa, Vázquez Montalbán señala la necesidad de generar una "subliteratura de agitación que rompa las barreras organizativas del sistema" (21), a la cual concibe como una posible expresión didáctico-popular que sea capaz de romper para siempre con el populismo que suele caracterizar esta clase de empeños. Opina además que para lograr esto es indispensable investigar a fondo las claves lingüísticas de la cultura de masas, pues esta literatura crítica que él propone como nueva opción (y que denomina "literatura auténticamente revolucionaria") ha de romper las barreras del lenguaje forjado por la cultura tradicional elitista de la burguesía.

Por su parte, Francisco Ayala, en su ensayo "La situación literaria en España", alude a otro de los "errores" cometidos por la llamada "generación del realismo": pensar que el ambiente social determina -y no sólo condiciona- la actividad artística. Por eso la literatura española se enfrenta, señala Ayala:

(...) a los inconvenientes de una poesía o de una novela que, a falta de cauces más idóneos, acude a suplir las tareas de la crítica político-social (...), históricamente acaso fue inevitable; pero sus resultados literarios se mostraron por lo común bastante pobres (1970: 24).

A propósito de ese tipo de consideraciones presentes en este número de Cuadernos para el diálogo, Eduardo G. Rico, en su artículo "Notas para un tiempo confuso", opina que la historia sobre la promoción socialrealista aún no se ha contado, aunque parezca que de ella ya se ha dicho todo; por eso, señala, "este número de Cuadernos da testimonio de la necesidad de volver, a pesar de todo, muchas veces aún sobre una revisión pendiente como la del socialrealismo" (1970: 24-5).

El Equipo Editorial Comunicación rubrica un ensayo titulado "La crítica literaria en España", y en él pasan revista a la crítica literaria española desde la posguerra hasta 1970. Apuntan que al margen de la crítica universitaria erudita (la de la Escuela de Menéndez Pidal) surgió la que ellos denominan "crítica comprometida", la cual se nutrió de Sartre, Machado y "un "marxismo de tradición oral", clandestinamente aprendido y divulgado" (1970: 33). Consideran que una de las principales características (y problemas) de esta crítica es el hecho de que, implícita o explícitamente:

(...) centra el problema en el valor social del arte, en su capacidad de transformación de la realidad histórica e incluso (...) en la "función justiciera" de los productos artísticos... Ello encierra una concepción contenidista del arte y la literatura que centraliza lo específicamente artístico sobre el eje forma-contenido, siendo éste una representación de la realidad que aquélla debe elaborar (1970: 34).

Asimismo, señalan estos autores que la "crítica comprometida" promovía la utilización de las técnicas objetivas de narración frente al subjetivismo del autor-dios, aunque luego se pudo comprobar que "la objetividad propuesta para el realismo no era tal, sus limitaciones para la descripción de la realidad eran evidentes" (1970: 35). 
Una crítica más que realizan a los "críticos comprometidos" se refiere a la disyuntiva lukacsiana naturalismo-realismo, ante la cual:

(...) los jóvenes críticos saludaron con alborozo algunas obras -como las de García Hortelano- y dieron en decir que representaban una indiscutible superación del naturalismo. El tiempo no ha tardado mucho en aclarar la situación: ni aquello era objetivismo, ni aquello era superación del naturalismo burgués (social-realismo, realismo-socialista, como quiera que se llamara) (1970: 35).

Pero lo que el Grupo Comunicación considera más denigrante de la crítica literaria del realismo español es su falta de autocrítica, en dos sentidos:

\begin{abstract}
En sentido negativo, pues ningún crítico se sintió comprometido con los acontecimientos realistas (ni siquiera todos los escritores lo hicieron) y, lejos de tratar de obtener conocimientos de sus experiencias anteriores, dan comienzo a una serie interminable de términos vejatorios, insultantes y reaccionarios, como si el pasado no fuera con ellos (...) Pero también crítica en sentido positivo, es decir, en el sentido de conectar eso que ellos llaman "hallazgo" con la tradición cultural del país, entroncándolos con la historia y el trabajo cultural autóctonos, en busca del humus donde desde el objetalismo al estructuralismo puedan convertirse en auténticas herramientas de conocimiento (...), es decir, frente al populismo sentimental del compromiso a los cuatro vientos, el elitismo hippiforme de la literatura novísima (1970: 37).
\end{abstract}

Así, se critica tanto el "exagerado" compromiso pregonado por los realistas sociales, como la incomunicación entre autor-texto y lector generada por los experimentalistas.

En este mismo número extraordinario XXIII, se publican las intervenciones realizadas en una mesa redonda sobre la novela, en la cual participaron Juan Benet, J.M. Caballero Bonald, José María Guelbenzu, Carmen Martín Gaite, A. Martínez Menchén e Isaac Montero. Entre los temas que allí se abordaron, aunque de una manera bastante desordenada, se encuentran los siguientes: novelística e individualidad, novela y sociedad, literatura y función social, el lenguaje de la novela, individuo, sociedad y literatura, literatura e invención, y la literatura como intento lúdico.

En términos generales, se puede afirmar que los participantes se dividieron en dos grupos, cada uno de los cuales mantuvo y defendió cierta posición: por un lado, Benet (el que más habló), Caballero Bonald, Martín Gaite y Guelbenzu plantearon que el novelista y la novela no estaban determinados por la realidad histórica y que la literatura no tenía por qué desempeñar una función social, es decir, que la invención, la singularidad y el genio son conceptos fundamentales en la literatura, y que la práctica literaria siempre ha de implicar un intento lúdico, más allá de todo compromiso político y de toda denuncia social. Por su parte, Montero y Martínez Menchén, todavía un tanto apegados a los postulados realistas, defendieron el planteamiento de que la novela ha sido, es y será aquello que en un momento determinado la sociedad imponga, que la novela representa el género literario que más se adecua al avance del pensamiento científico, en tanto que reflejo de lo real, que la novela sí tiene una función social, que la novela experimental es elitista porque sólo puede ser comprendida por unos pocos, en fin, que la literatura nunca puede separarse de la sociedad y que la evolución literaria está ligada a determinaciones históricas concretas. ${ }^{8}$

En 1971 se publica el suplemento No. 19, titulado "Literatura y política (en torno al realismo español)". Aún en esta fecha el tema del realismo social no se había agotado, a pesar 
de que como "corriente literaria" o como "técnica narrativa" prácticamente ya había dado sus últimos suspiros y ahora se convertía en protagonista de la escena literaria el llamado experimentalismo.

Eduardo G. Rico aparece como firmante de este suplemento y es él quien elabora la extensa introducción que precede a las respuestas que varios escritores, poetas, novelistas y críticos dieron a diversas preguntas planteadas por Cuadernos para el diálogo acerca de la literatura social ${ }^{9}$.

La premisa básica con que Rico arranca su análisis es la siguiente:

\begin{abstract}
Nunca se insistirá bastante en subrayar que toda postura establecida con respecto a los demás y al contexto integrado por las ideas en vigor, las instituciones, las estructuras sociales, entraña una apuesta política, inevitablemente trasladada, cuando es escritor quien la asume, a su obra literaria, aunque no aparezca en ésta expresamente formulada. Todos somos políticos, queramos o no, en alguna medida, y el escritor también (...) Esta constatación (...) no debe dificultar, de ningún modo, el reconocimiento de la especificidad del arte, de su relativa autonomía (...) El "compromiso" no vicia o inutiliza necesariamente la obra de arte (1971: 5).
\end{abstract}

Luego de brindar elementos para la definición de la literatura social, apoyándose en críticos -en algunos casos también escritores- tales como Pablo Gil Casado, Raúl Morodo, José María Castellet, Alarcos Llorach, Eugenio de Nora y Gabriel Celaya, el autor realiza un recorrido por la novela española de los cuarenta y cincuenta, la analiza desde una perspectiva bastante crítica con respecto a los postulados más radicales del realismo social -que él denomina "escuela cívico-literaria"- y con respecto a las obras y muchas de las nociones que la crítica literaria había "sacralizado" o "fijado", y concluye lo siguiente:

Cabe también pensar, al considerar la vida efímera de esta novelística —no alcanzó los dos lustros su vigencia; ya en 1963 entraba en pleno agotamiento-, que al ser concebida como "literatura de urgencia", la obra apresurada de los "sociales" no pudieran perdurar por su torpeza técnica, inadvertida en un momento de crisis, pero notoria en una situación de mayor sosiego; fue la suya una fórmula provisional, oportuna un instante y desfasada en seguida, que perdió pie al intensificarse el ritmo de los hechos sociológicos y aumentar la capacidad del sistema para la asimilación de los conflictos, al formalizarse una nueva política "liberalizante" que vació de contenido a la rebeldía literaria tal como se venía manifestando. La novela social nunca había llegado al corazón de la realidad, ni se había parado en el esfuerzo de interpretar y valorar la auténtica raíz de los hechos. Moriría con su tiempo, un tiempo muy breve. El desaliento que produciría su extinción conduciría a algunos, por reacción, al extremo opuesto: a un esteticismo dogmático (Rico 1971: 17).

\title{
5. $\quad$... Y pasamos a otros temas
}

Parece ser que después de la aparición de este suplemento sobre "Literatura y política", en Cuadernos para el diálogo decreció el interés por el tema literario, pues entre 1972 y 1975 se publicaron muy pocos artículos relacionados con esta temática, lo cual es aún más evidente si tomamos en cuenta la cantidad de ensayos que aparecieron entre 1963 y 1971. La polémica sobre literatura social había finalizado y ahora se daba paso a otras preocupaciones. 
En 1972, año internacional del libro, se editó un número extraordinario —el No. XXXII— dedicado más bien a los avatares del libro, es decir, a la situación y las perspectivas de la industria editorial española. En su extenso titulo se deja entrever muy bien la problemática que ahora es objeto de interés: "Que trata de los libros y su industria, las censuras, las culturas -la establecida y la por establecer- clases sociales, ideologías y algunas cosas más que también tienen que ver con la actividad editorial".

En 1974 se publicó el número extraordinario XLII, titulado “¿Existe una cultura española?", y en él aparecieron tres artículos relacionados con la literatura. En el primero de ellos, "Aires del exterior", Rafael Conte se refiere a las diversas "influencias exteriores" que recibieron los escritores españoles de la posguerra. Señala que los autores de la llamada generación del realismo social se vieron influidos, aunque de manera desarticulada, informal, desordenada y asistemática, por los siguientes:

\footnotetext{
Por una parte, Sartre y el existencialismo comprometido; por otra, la literatura del neorrealismo italiano (...); también la generación perdida americana. Y formando un todo verdaderamente revuelto con ello, llegaban a manos inocentes los libros aislados de un tal Lukacs, los escritos teóricos sobre arte literario de un Sartre o de un Trotsky, el crítico más dotado del marxismo internacional (1974: 302).
}

Por su parte, José María Castellet publica "Para una crítica de la crítica", ensayo en el que acusa a la crítica literaria de poseer un tono general de mediocridad -aspecto en el que emula a la actual literatura de creación y que evidencia su falta de planteamientos propios-, a pesar de que en su opinión la crítica debe ser autónoma frente a la "calidad" de la literatura que se produce en un momento determinado.

Castellet opina que la literatura de creación se encuentra en crisis y necesita una gran renovación, por lo tanto, considera que lo más sensato que puede hacer la crítica literaria es distanciarse y generar su lenguaje particular en torno a las propuestas renovadoras, empleando la ironía como arma fundamental.

El último de los artículos, firmado por JulioVélez y titulado "Monopolización de los premios literarios", ya fue comentado en otra parte de este trabajo.

\section{Conclusión}

La literatura, y en particular la literatura social, es un tema recurrente en la revista Cuadernos para el diálogo durante los años de su publicación que se han revisado para este ensayo: 1963-1975.

A pesar de que cuando apareció el primer número de esta revista -en 1963- ya muchos escritores, editores y críticos daban prácticamente por muerto al realismo social, se pregonaba su agotamiento y se planteaba la necesidad de incursionar en técnicas narrativas novedosas que sacaran a la novela española del bache en el que había caído, en Cuadernos para el diálogo se continuó debatiendo durante varios años, aproximadamente hasta 1971, acerca de la validez de la literatura social, el "compromiso" (social-político) del escritor y su "libertad" en tanto creador, la capacidad de la literatura para transformar la realidad, la relación entre literatura y sociedad, la determinación ejercida por la sociedad sobre la literatura y su evolución, 
entre otros temas. Poco se hablaba del experimentalismo, aunque, en términos generales, cuando se aludía a él se criticaba su "elitismo" y la incomunicación que generaba entre el lector y el texto experimental.

Tres años $(1969,1970$ y 1971) resultan especialmente productivos en lo que respecta a la publicación de ensayos relacionados con estos temas, gracias a la publicación de dos números extraordinarios —el número XIV y el número XXIII- y un suplemento —el número 19 - que se centran exclusivamente en la literatura social.

El primero de estos números monográficos dio origen a una polémica tal que los editores de la revista se felicitaron por ser los responsables de generarla a tal punto que decidieron publicar otro monográfico sobre literatura al año siguiente, y otro más sobre literatura y política un año después.

Esta investigación no se ha dedicado a determinar qué tipo de relación existía entre Cuadernos para el diálogo y la censura, pero lo cierto es que en muchos de los ensayos allí publicados se pueden encontrar, sin necesidad de rebuscar demasiado, duras críticas al régimen dictatorial español, las cuales al parecer no eran sancionadas por los órganos censores, puesto que aparecían una y otra vez en las páginas de esta revista.

Queda para futuras investigaciones el análisis de este y otros temas de gran relevancia para la literatura española contemporánea, presentes en la revista Cuadernos para el diá$\log o$ y en otras revistas culturales españolas.

\section{Notas}

1. Nos referimos al número extraordinario XIV, "30 años de literatura narrativa y poesía española. 19391969" (mayo, 1969); al número extraordinario XXIII, "Literatura española: a 30 años del siglo XXI" (diciembre 1970) y al suplemento número 19, 1971.

2. Para profundizar en estos aspectos se pueden confrontar, entre otros, los siguientes textos: Gil Casado, Pablo. La novela social española. Barcelona: Editorial Seix Barral, 1968; Corrales Egea, José. La novela española actual. (Ensayo de ordenación). Madrid: Editorial Cuadernos para el diálogo, 1971; Sanz Villanueva, Santos. Historia de la literatura española 6/2. Literatura actual. Barcelona: Editorial Ariel, 1984; Encinar, Ángeles. Novela española actual: la desaparición del héroe. Madrid: Editorial Pliegos, 1990; Asís, María Dolores de. Última hora de la novela en España. Madrid: EUDEMA, 1992. Resulta particularmente interesante el análisis realizado por Francisco Álamo Felices en su texto La novela social española. Conformación ideológica, teoría y crítica. Almería: Universidad de Almería, 1996, pues a lo largo de las 236 páginas del libro su autor procura releer desde una óptica bastante desmitificadora, tanto las novelas sociales "sacralizadas" por la crítica literaria, como las interpretaciones y periodizaciones elaboradas por los críticos para explicar este proceso de surgimiento, crecimiento y crisis final de la novela social, así como el contexto histórico español en que se dio esta literatura.

3. Para la distinción entre "neorrealistas" y "realistas sociales" y la "evolución" de muchos de estos novelistas desde el realismo social más radical hacia otras alternativas literarias, cf. Santos Sanz Villanueva. 1984. Historia de la literatura española 6/2. Literatura actual. Barcelona: Ariel (pp. 104-41).

4. No hay ni uno sólo de los libros que aborden la temática de la novela española contemporánea o de posguerra que no lo mencionen como obra de ruptura y como hito en la narrativa española de posguerra. 
5. Una de las características que los críticos literarios señalan al referirse a los autores del realismo social es su escasa preocupación por los aspectos formales. El contenido lo era "todo".

6. También aparece un artículo dedicado a la novela catalana y otro a la novela gallega. Cf. el listado de artículos que aparece al final de este trabajo. Curiosamente no se publica ningún ensayo sobre la novela vasca.

7. En el artículo titulado "Los premios literarios o treinta años de falsa fecundidad", publicado también en el número extraordinario XIV, Isaac Montero realiza una cruda crítica al "mecanismo comercial” que en su opinión constituyen los premios literarios. Habla incluso de corrupción y sucios manejos en el proceso que implica el otorgamiento de estos galardones y concluye que "a la alienación del hombre por la vía de un consumo mixtificador y por la totalitaria de la amputación de la realidad, sirven y han servido los premios literarios de nuestra posguerra" (1969: 84). Por su parte, Julio Vélez también publica, en 1974, un artículo sobre los premios, titulado "Monopolización de los premios literarios". Este autor, al igual que Montero, presenta una postura bastante crítica ante los premios literarios y los considera "fieles guardianes de nuestra cultura oficial" (311). Vélez concluye lo siguiente: "Los premios literarios fructifican en proporción directa a las dificultades de publicación. El día que los escritores tengan facilidad de acceso a las editoriales, los premios literarios se irán progresivamente reduciendo, siendo esto reflexivo de una democratización a todos los niveles, tanto cultural como político y económico" (316).

8. A raíz de esta mesa redonda y del enfrentamiento entre estas dos posturas, surgió una agria polémica personal entre Juan Benet e Isaac Montero, la cual se concreta en la publicación de los siguientes artículos, también aparecidos en el número extraordinario XXIII: “Acotación a una mesa redonda. (Respuestas a Juan Benet y defensa apresurada del realismo)", por Isaac Montero (1970: 65-74), y "Respuesta al señor Montero", por Juan Benet (1970: 75-6).

9. Los entrevistados fueron: Carlos Barral, Juan Benet, José Manuel Caballero Bonald, Gabriel Celaya, José Esteban, Juan García Hortelano, Francisco García Pavón, Ángel González, Félix Grande, Alfonso Grosso, José María Guelbenzu, Armando López Salinas, Alberto Míguez y Juan Pedro Quiñonero. Aunque las preguntas podían variar de uno a otro entrevistado, las interrogantes fundamentales fueron: ¿Qué entiende por literatura social? ¿Aún mantiene su vigencia la literatura social? ¿Cree que la literatura es capaz de transformar el mundo?

Es pertinente señalar que, en la mayoría de los casos, los entrevistados dan cuenta de su evolución personal desde una postura de apego y defensa de los postulados del "realismo social" hacia una postura más escéptica y menos "comprometida" (al menos en lo que respecta al compromiso político). Esta "evolución” se aprecia claramente en las respuestas dadas a la pregunta: ¿Cree que la literatura es capaz de transformar el mundo?, a la cual muchos respondieron rotundamente que no.

\title{
Bibliografía
}

Álamo Felices, Francisco. 1996. La novela social española. Conformación ideológica, teoría y crítica. Almería: Universidad de Almería.

\author{
Asís, María Dolores de. 1990. Última hora de la novela en España. Madrid: Universidad \\ Complutense de Madrid.
}

Bosh, Rafael. 1971. La novela española del siglo XX. De la república a la posguerra (Las generaciones novelísticas del 30 y del 60). Nueva York: Las Américas. 
Cardona, Rodolfo (ed.). 1976. Novelistas españoles de posguerra. Madrid: Taurus.

Corrales Egea, José. 1971. La novela española actual (Ensayo de ordenación). Madrid: EDICUSA.

Dolgin, Stacey L. 1991. La novela desmitificadora española (1961-1982). Barcelona: Anthropos.

Encinar, Ángeles. 1990. Novela española actual: la desaparición de héroe. Madrid: Editorial Pliegos.

Ferreras, Juan Ignacio. 1970. Tendencias de la novela española actual (1931-1969). París: Hispanoamericanas.

García-Viñó, Manuel. 1975. La novela española actual. Madrid: Guadarrama.

Gil Casado, Pablo. 1968. La novela social española. Barcelona: Seix Barral.

1990. La novela deshumanizada española (1958-1988). Barcelona: Anthropos.

Goytisolo, Juan. 1967. El furgón de cola. Barcelona: Seix Barral.

Nora, Eugenio de. 1971. La novela española contemporánea. III (1939-1967). 2a. edición. Madrid: Gredos.

Sanz Villanueva, Santos. 1980. Historia de la novela social española (1945-1975). 2 volúmenes. Madrid: Alhambra.

1984. Historia de la literatura española 6/2. Literatura actual. Barcelona: Ariel.

\section{Listado de artículos analizados, todos ellos tomados de la revista Cuadernos para el diálogo:}

Ayala, Francisco. 1970. "La situación literaria en España”. Número extraordinario XXIII. "Literatura española a 30 años del siglo XXI": 23-4.

Barral, Carlos. 1969. "Reflexiones acerca de las aventuras del estilo en la penúltima literatura española”. Número extraordinario XIV. "30 años de literatura narrativa y poesía española. 1939-1969": 39-42.

Benet, Juan. 1970. "Respuesta al señor Montero”. Número extraordinario XXIII. "Literatura española a 30 años del siglo XXI": 75-6. 
Castellet, José María. 1974. "Para una crítica de la crítica.” Número extraordinario XLII. “Existe una cultura española?”: 309-10.

Castillo Puche, José Luis. 1963. "Compromiso del escritor con el hombre de su tiempo". (1):12-3.

Clotas, Salvador. 1969. "Meditación precipitada y no premeditada sobre la novela en lengua castellana". Número extraordinario XIV. "30 años de literatura narrativa y poesía española. 1939-1969": 7-18.

Conte, Rafael. 1974. “Aires del exterior”. Número extraordinario XLII. “¿Existe una cultura española?”: 302-4.

Díez Borque, José María y Santos Sanz Villanueva. 1970. "Sociología del fenómeno literario. Encuesta." Número extraordinario XXIII. "Literatura española a 30 años del siglo XXI": 77-91.

Editores. 1960. "Encuesta. II. La novela”. Número extraordinario XIV. "30 años de literatura narrativa y poesía española. 1939-1969”: 63-70.

Editores. 1969. "Polémica sobre literatura". (68): 10.

Editores. 1970. "Polémica en la prensa". Número extraordinario XXIII. "Literatura española a 30 años del siglo XXI": 93-8.

Editorial. 1970. “Tiempo de polémica”. Número extraordinario XXIII. "Literatura española a 30 años del siglo XXI": 3-4.

Editorial. 1969. “QQué es la literatura?” Número extraordinario XIV. “30 años de literatura narrativa y poesía española. 1939-1969": 5-6.

Ferres, Antonio. 1965. “Literatura y sociedad”. (17): 15-7.

Ferres, Antonio. 1965. "Evolución de la novela española". (27): 25-8.

Fuster, Joan. 1969. "Literatura en lengua catalana". Número extraordinario XIV. "30 años de literatura narrativa y poesía española. 1939-1969": 19-21.

Grupo Comunicación. 1970. "La crítica literaria en España”. Número extraordinario XXIII. "Literatura española a 30 años del siglo XXI": 31-7.

Guelbenzu, José María. 1968. “Literatura, una insoportable soledad”. Número extraordinario VII. "Comienzo de un camino. Octubre de 1963-diciembre de 1967. Cuatro años.

Cincuenta números": 47-50. 
Ibarrola, Alonso. 1970. "Narrativa humorística española". Número extraordinario XXIII. "Literatura española a 30 años del siglo XXI".

López Salinas, Armando. 1965. "Notas para un diálogo sobre el realismo en literatura". (19): 15-7.

Losada, Basilio y Xosé Luis Méndez Ferrín. 1969. "Literatura en lengua gallega”. Número extraordinario XIV. "30 años de literatura narrativa y poesía española. 1939-1969”: 22-6.

Martín Serrano, Manuel. 1967. "Miguel Ángel Asturias habla de la novela hispanoamericana”. Número extraordinario VI. "Cultura hoy": 95-8.

Martínez Menchén, Antonio. 1964. “Subdesarrollo literario”. (14): 18-9.

1967. “La enajenación del escritor”. Número extraordinario VI. "Cultura hoy”: 61-2.

Medio, Dolores. 1965. "El feminismo en la novela española”. Número extraordinario. "La mujer".

1966. “Comentarios en torno a la novela social”. (29): 29-32.

Montero, Isaac. 1969. "Los premios o treinta años de falsa fecundidad”. Número extraordinario XIV. “30 años de literatura narrativa y poesía española. 1939-1969”: 73-84.

1970. "Polémica. Acotación a una mesa redonda. (Respuestas a Juan Benet u defensa apresurada del realismo". Número extraordinario XXIII. "Literatura española a 30 años del siglo XXI": 65-74.

Morán, Fernando. 1964. "Novela y realidad social”. (4): 16-9.

1969. "La novela: entre el subdesarrollo y la sociedad de masas”. Número extraordinario XV: 61-70.

Peñalva, Pedro. 1965. “"Los comisarios secretos”: Julián Marías o la honradez intelectual”. (21-22): 36-7.

Pérez-Minik, Domingo. 1970. "Las conexiones y las recuperaciones. Los amores imposibles con la novela extranjera". Número extraordinario XXIII. "Literatura española a 30 años del siglo XXI": 39-41.

Rico, Eduardo G. 1970. "Notas sobre un tiempo confuso". Número extraordinario XXIII. "Literatura española a 30 años del siglo XXI": 25-7. 
1971. "Literatura social: "podemos definirla"”. (19): 6-17.

Santos, Félix. 1973. "Libertad de expresión y censura previa". Número extraordinario XXXV, "Libertades públicas en España": 244-6.

Sastre, Alfonso. 1964. "Aproximación a la estética”. (7): 12-4.

1965a. "Los comisarios secretos." (18): 19-21.

1965b. "Los comisarios secretos. (23-24): 45.

1967. "Sobre el momento actual de la crítica literaria y artística en España". (50): 34-5.

Vallverdu, Frances. 1972. “¿Quién hace el libro y para quién se hace?” Número extraordinario XXXII. "Que trata de los libros y su industria, las censuras, las culturas — la establecida y la por establecer - clases sociales, ideologías y algunas cosas más que también tienen que ver con la actividad editorial": 288-91.

Valverde, José María.1970. "Los puntos de partida de la literatura española moderna. Miradas para cien años." Número extraordinario XXIII. "Literatura española a 30 años del siglo XXI": 5-8.

Varios. 1970. "Mesa redonda: novela." Número extraordinario XXIII. "Literatura española a 30 años del siglo XXI": 45-51.

Varios. 1972. "Mesa redonda: Miseria, negocio, cultura, manipulación y libertad del libro en España". Número extraordinario XXXII. "Que trata de los libros y su industria, las censuras, las culturas -la establecida y la por establecer- clases sociales, ideologías y algunas cosas más que también tienen que ver con la actividad editorial": 314-25.

Vázquez Montalbán, Manuel. 1970. “Aciertos y carencias de la literatura española moderna. Tres notas sobre literatura y dogma". Número extraordinario XXIII. "Literatura española a 30 años del siglo XXI": 17-22.

Vélez, Julio.1974. "Monopolización de los premios literarios". Número extraordinario XLII. “¿Existe una cultura española?”: 311-6.

Verdura, Josep. 1972. "Libros para los obreros (divagaciones sobre la marcha)". Número extraordinario XXXII. "Que trata de los libros y su industria, las censuras, las culturas —la establecida y la por establecer- clases sociales, ideologías y algunas cosas más que también tienen que ver con la actividad editorial": 292-5. 